\title{
The Development of Village Health Volunteers' Competencies for Tuberculosis Care in Trang Province, Thailand
}

\author{
Jiraporn Choowong $^{1}$, Duangjai Sawatdee ${ }^{1}$ Penjan Maneechote $^{1} \&$ Phatcharapon Tulyakul $^{1,2}$ \\ ${ }^{1}$ Boromarajonani College of Nursing Trang, Praboromarajchanok Institute for Health Workforce Development \\ (PIHWD), Ministry of Public Health, Thailand \\ ${ }^{2}$ Kramer School of Nursing, Oklahoma City University, USA \\ Correspondence: Jiraporn Choowong, Boromarajonani College of Nursing Trang No. 91 Kok Kun Road, Tubtieng \\ Sub-district, Muang District, Trang 92000, Thailand. Tel: 66-75-211-298 ext. 127. E-mail: jirapornc@bcnt.ac.th; \\ choowong14@hotmail.com
}

Received: April 27, 2020 Accepted: June 18, 2020 Online Published: June 26, 2020

doi:10.5539/gjhs.v12n9p30 URL: https://doi.org/10.5539/gjhs.v12n9p30

\begin{abstract}
Background: Tuberculosis (TB) is a major public health concern resulting in high rates of morbidity and mortality worldwide, particularly in low- and middle-income countries, despite treatment having been available for over 50 years. It remains a crucial health problem in Thailand. This study aimed to develop a program for building tuberculosis (TB) care competencies of village health volunteers (VHVs) and to examine its effects on the outcomes of care for TB patients.
\end{abstract}

Methods: The competency development program (CDP) was developed based on the principles of empowerment and community-based TB care. Forty VHVs in two villages of Khoglor sub-district, Trang, Thailand were recruited. Participants were classified into control and experimental groups equally $(\mathrm{n}=20)$ by using a matched pair technique.

Results: The results showed that the mean scores of TB knowledge, attitude towards TB care, and TB care skills in the experimental group at the baseline and post-intervention were significantly different $(p<0.05)$. The mean scores of TB knowledge, attitude towards TB care, and TB care skills in the experimental and control groups at the baseline were not different. However, the scores of these three competencies at the post-intervention were significantly higher in the experimental group, compared to the control group $(p<.05)$.

Conclusion: Per the findings of the study, healthcare professionals should incorporate the principles of empowerment and community-based TB care in TB training programs in order to enhance TB care competencies of community health volunteers.

Keywords: Competency development program, Empowerment, Tuberculosis, Village health volunteers

\section{Background}

Tuberculosis (TB) is a major public health concern resulting in high rates of morbidity and mortality worldwide, particularly in low- and middle-income countries, despite treatment having been available for over 50 years. It remains a crucial health problem in Thailand (Bureau of Tuberculosis, Department of Disease Control, 2018). This disease affects not only TB patients, but also their family members and other people who have had close contact with the patients. These people experienced adverse physio-psychological effects of the disease, such as, increased distress, depression, and a negative stigma surrounding this disease (Koyanagi, et al. 2017; Namwat et al., 2018). Furthermore, TB patients in low-and middle-income countries tend to face economic burden due to the high cost of treating disease and loss of income (Tanimura, Jaramillo, Weil, Raviglione, \& Lönnroth, 2014). Even though the World Health Organization (WHO) declared TB to be a global health emergency and has called on all nations to combat this disease for more than two decades, the decrease of TB incidence was only $2 \%$ per year (WHO, 2018). The WHO (2018) classified high-burden countries for TB into three categories: 1) high TB burden, 2) high TB/HIV burden, and 3) high multidrug-resistant TB (MDR-TB) burden. Forty-eight countries were cited in these three high-burden county lists for TB (WHO, 2018).

Thailand was classified as one of the top twenty countries that had the highest incidences of TB, TB/HIV, and MDR-TB burden (WHO, 2018). The WHO predicted that Thailand would reach 120,000 TB cases by 2016, which 
would include 15,000 TB patients with HIV and 4,500 MDR-TB patients (WHO, 2015). However, only 70,114 registered patients with first TB diagnosis and relapse were reported in 2016 (Bureau of Tuberculosis, Department of Disease Control [DDC], 2018). Of these reported patients, $11 \%$ were TB patients with HIV and $1.35 \%$ were patients with MDR-TB (Bureau of Tuberculosis, DDC, 2018). Thailand is facing a big challenge of TB management because the TB treatment success rate for new TB patients in Thailand is lower than the global rate (Bureau of Tuberculosis, DDC, 2018; WHO, 2018). In addition, the incidence of MDR-TB burden in relapsed patients was six times higher than in new cases (Bureau of Tuberculosis, DDC, 2018). Patients with MDR-TB, therefore, were more likely to develop extensively drug-resistant tuberculosis (XDR-TB) (WHO, 2018). In the past fifteen years, the TB incidence in Thailand decreased by only $2.7 \%$ per year (Namwat et al., 2018).

Because of the severity of the TB situation in Thailand, the Department of Disease Control (DDC) (2017) established the National Strategic Plan on TB (2017-2021). This plan was developed based on the end TB strategy of the WHO, with the end goals in mind of preventing, treating, and controlling the spread of this disease (DDC, 2017). The DDC (2017) set the goal that the TB incidence rate in Thailand must decline at least $12.5 \%$ per year and the mortality rate in TB patients must decrease at least $50 \%$ by 2021 . To accomplish these two goals, the DDC established five strategies including screening those on the high-risk population for TB, reducing the mortality rate in TB patients, establishing sustainable strategic management, enhancing healthcare providers' capacities and promoting researches and innovations for preventing, curing, and controlling TB. According to the DDC (2017), $90 \%$ of people who were at risk of TB infection must receive TB screening, such as people with HIV infection, people with type II diabetes, prisoners, and migrant workers. In addition, all new TB cases must be treated by using a patient-centered care strategy in order to increase the TB treatment success rate. To promote the success of TB treatment and control, all levels of the health system are required to implement the National Strategic Plan on TB.

Trang province is under the jurisdiction of the regional health 12, Thailand. In 2018, the Trang Provincial Public Health Office (2019) noted a total of 538 registered TB patients in Trang, representing a 17\% decrease from 2017. Only $2.7 \%$ of registered cases in 2018 succeeded in TB treatment (Trang Provincial Public Health Office, 2019). However, a total number of registered TB patients in 2019 increased 11\% from 2018 (Trang Provincial Public Health Office, 2019). Furthermore, 17\% of relapsed TB patients in 2019 became MDR-TB (Trang Provincial Public Health Office, 2019). These data indicate a failure of the existing healthcare system for care of TB patients at the province level because healthcare professionals, caregivers, and TB patients have been facing many challenges and obstacles relating to TB screening and treatment (Choowong, Tillgren, \& Söderbäck, 2016; 2017; 2018; Kaji, Thi, Smith, Charunwatthana, \& Nosten, 2015). Challenges of healthcare professionals prohibiting the success of the End TB strategy were lack of collaboration between these stakeholders and lack of an effective follow-up system (Kaji et al., 2015). In addition, TB patients themselves faced challenges due to low socioeconomic status, lack of knowledge and motivation to complete TB treatment, the stigma surrounding having TB, dissatisfaction with DOT program, and mistrust of DOT caregivers (Choowong et al., 2017; 2018; 2019; Ruanka, 2019). Using community health volunteers (CHVs) who were trained for TB care was an effective community-based TB care strategy because they could help healthcare professionals to screen those suspected of having TB, provide TB prevention information to communities, and support the DOT administration (Balogun, 2015; Ngamvithayapong-Yanai, Luangjina, Nedsuwan, Kantipong, Wongyai, \& Ishikawa, 2013; Rakwong, Sillabutra, \& Keiwharnka, 2010; WHO, 2015).

Many provinces in Thailand, including Trang prepared village health volunteers (VHVs) to provide care for TB patients at a local community level (Choowong et al., 2016; Chuaihom, 2018; Ngamvithayapong-Yanai et al., 2013; Somrit, 2015; Vachirabunchong, 2015). Many strategies were used to enhance TB care competencies of VHVs, such as training sessions and empowerment programs (Choowong et al., 2019; Escott \& Walley, 2005; Lewis \& Newel, 2009). Even though VHVs were trained for providing care for TB patients, they still lacked confidence in their knowledge and skills that resulted on providing ineffective care for TB patients (Choowong et al., 2017; Chuaihom, 2018). To enhance VHVs' competencies for TB caring, VHVs must be trained through empowerment programs to enhance self-confidence in their knowledge and skills (Bureau of Tuberculosis Department of Disease Control, 2017). This study, therefore, aimed to develop a program for building VHVs' TB care competencies and to examine its effects on the outcomes of care for TB patients in Khoklor subdistrict, Trang province.

\section{Research Methodology}

\subsection{Research Design}

This study utilized a quasi-experimental approach with pretest-posttest control group design focusing on developing the competency development program (CDP) and examining its outcomes on VHVs' TB care competencies. 


\subsection{Study Setting}

According to Trang Provincial Public Health Office (2019), the highest TB prevalence and high TB morbidity rate in Trang province were found in Mueang district. To specify the research area, a sample random technique was used to select one subdistrict out of fifteen subdistricts in Mueang district. Khoklor subdistrict was randomly chosen. Then, two villages in Khoklor subdistrict were selected as the research area.

\subsection{Study Population}

The target population of this study was 1,591 VHVs in Trang province. VHVs who met these following inclusion criteria were included in the study: 1) lived in Khoklor subdistrict, Mueang district, 2) had experiences in providing care for TB patients at least one year, 3) were able to read and write in Thai fluently, and 4) gave consent to participate in the study. To calculate the sample size for this study, the $G^{*}$ Power program (Version 3.1) was used at the power analysis of 0.85 for $\pm 5 \%$ of a precision level, $95 \%$ confidence level $(\mathrm{p}=.05)$. The minimum sample size of participants in a two-group experiment was 38. To prevent incomplete response and data error, the researcher added more $5 \%$ of the smallest sample size. The final anticipated samples, therefore, were forty VHVs participants. Participants were classified into control and experimental groups equally $(n=20)$ by using a matched pair technique. Furthermore, each group was located in a different village to prevent contamination in the intervention.

\subsection{Development and Validation of Competency Program}

The focus and the contents of CDP were developed based on the concepts of empowerment (Gibson, 1991; Tengland, 2008) and community-based TB care through a participatory workshop. The researchers also developed the TB care handbook for VHVs. The contents of the CDP and TB care handbook were related to community-based TB control methods in terms of TB screening, treatment, and prevention. Five experts rated the nine indicators on a four-point scale for the appropriateness and feasibility of the handbook and CDP. These indicators were considered appropriate and feasible based on the interquartile range (IQR) of 1.5 or lower. The results showed that IQRs of all indicators ranged from 0.45 to 0.95 . Then, the handbook and CDP were revised following the experts' suggestions.

\subsection{The CDP Intervention}

The CDP consisted of three workshops in a four-week duration. Participants in the experimental group were asked to participate in these workshops. In contrast, participants in the control group did not receive any interventions. Before the first workshop began, participants in both groups were pre-tested according to their knowledge, attitudes, and skills for TB care. In the first workshop, researchers conducted brainstorming and training sessions. Participants in the experimental group and researchers collaboratively analyzed a current TB situation within the village, and then established expectations and strategies to manage that specific situation related to TB. Next, participants were trained on how to screen, care, and prevent TB. At the end of this training session, participants were assigned to practice TB care for families in the target village.

The second workshop was initiated two weeks after the first workshop. In this workshop, researchers allowed participants to share their experiences and problems involving TB care during the past two weeks. Researchers also implemented the empowerment principle to provide more TB care training and suggestions for participants. At the end of this workshop, researchers and participants summarized problems and barriers for providing TB care in the village and then established the possible strategies to solve and diminish these problems and barriers. Participants were again asked to oversee their assigned families. After two weeks, the last workshop was set up for participants in both groups. All participants were post-tested their knowledge, attitudes, and skills for TB care.

\subsection{Data Collection}

The TB care questionnaire was used to evaluate the participants' TB care competencies developed by the researchers. The instrument consisted of four parts: demographics, knowledge, attitudes, and skills. The instrument was tested the content validity index (CVI) by three experts. The CVIs of knowledge, attitudes, and skills items were $.90, .80$, and .89 , respectively. The first part was five questions related to demographics. In the second part, TB knowledge was measured by twenty questions that allowed participants to choose true or false in response to statement questions on which responses ranged from 0 (incorrect) and 1 (correct). TB knowledge score was the sum score of responses on twenty items and ranged from 0 to 20 . Scores ranging from 17 to 20 indicated a high level of TB knowledge; whereas, scores ranging from 10 to 16 and 0 to 9 indicated a moderate to low level of TB knowledge, respectively. This scale showed good internal consistency reliability with Cronbach's alpha equal to 0.75 . In the third part of the questionnaire, attitude towards TB care was measured using ten items. The item was a five-point Likert scale on which responses ranged from 1 (totally disagree) to 5 (totally agree). 
This scale showed good internal consistency reliability with Cronbach's alpha equal to 0.85 . The final part of the questionnaire measured TB care skills using ten items with a five-point Likert scale of 1 (never), 2 (sometimes), 3 (often), 4 (very often), and 5 (always). This scale showed good internal consistency reliability with Cronbach's alpha equal to 0.90 .

\subsection{Data Analysis}

Descriptive statistics were used to summarize demographic characteristics of the sample. Comparisons of TB knowledge score, attitudes toward TB care score, and score on TB care skills between control and experiment were assessed using the independent sample t-test. To evaluate the effectiveness of the CDP, the paired sample t-test was used to compare TB knowledge score, attitudes toward TB care score, and score on TB care skills at the baseline and post-intervention. A probability of $p<0.05$ was considered statistically significant for all tests.

\subsection{Ethical Consideration}

The study was approved by the Ethics Review Committee, Boromarajajonani Collage of Nursing, Trang (ERC approval No: 30/2018). Participants were informed of information regarding the research topic, purpose, data collection process, potential risks, possible benefits, required participant activities, statement of confidentiality, and right to withdraw from the study. Participants decided to participate and gave informed consent without coercion prior to the beginning of the study.

\section{Results}

All participants were female. Most participants were aged 51 years and older. Participants came from different educational backgrounds. Most participants completed junior high school (32.5\%), elementary school (17.5\%), and bachelor's degree (17.5\%). Most participants were married (70\%). Participants reported having adequate family income and dept equally $(42.5 \%, 42.5 \%)$ (see Table 1$)$.

Table 1. Demographic Characteristics of Participants

\begin{tabular}{|c|c|c|c|c|c|}
\hline Demographics & $\begin{array}{l}\text { Experimental } \\
\text { group }(n=20)\end{array}$ & $\begin{array}{l}\text { Control group } \\
(n=20)\end{array}$ & Percentage & $X^{2}$ & p-value \\
\hline \multicolumn{6}{|l|}{ Genders } \\
\hline Female & 20 & 20 & 100 & & \\
\hline Age (years) & & & & 7.45 & .114 \\
\hline $30-40$ & 2 & 2 & 10.0 & & \\
\hline $41-50$ & 4 & 5 & 22.5 & & \\
\hline$>50$ & 14 & 13 & 67.5 & & \\
\hline Educational background & & & & 16.32 & 0.430 \\
\hline Elementary school & 4 & 3 & 17.5 & & \\
\hline Junior high school & 7 & 6 & 32.5 & & \\
\hline Senior high school/Vocational certificate & 4 & 6 & 25 & & \\
\hline Diploma/High vocational certificate & 2 & 1 & 7.5 & & \\
\hline Bachelor's degree & 3 & 4 & 17.5 & & \\
\hline Marital status & & & & 2.86 & 0.969 \\
\hline Single & 3 & 3 & 15 & & \\
\hline Widow & 2 & 1 & 7.5 & & \\
\hline Marriage & 14 & 14 & 70 & & \\
\hline Divorce/Separate & 1 & 2 & 7.5 & & \\
\hline Family economy status & & & & 5.77 & 0.449 \\
\hline In debt & 9 & 8 & 42.5 & & \\
\hline Barely adequate & 3 & 3 & 15 & & \\
\hline Adequate & 8 & 9 & 42.5 & & \\
\hline
\end{tabular}


The results in Table 2 depicted that the mean scores of TB knowledge, attitude towards TB care, and TB care skills in the experimental group at the baseline and post-intervention were significantly different at the $p$-value of 0.05 . Similarly, there were significant differences in the mean scores of attitudes toward TB care and TB care skills at the baseline and post-intervention in the control group (see Table 3).

Table 2. Comparisons of TB Knowledge, Attitudes toward TB Care, and TB Care Skills at the Baseline and Post-Test in the Control Group

\begin{tabular}{|c|c|c|c|c|c|c|}
\hline \multirow[t]{2}{*}{ Competencies } & \multicolumn{2}{|c|}{$\begin{array}{l}\text { Baseline } \\
(\mathrm{n}=\mathbf{2 0})\end{array}$} & \multicolumn{2}{|c|}{$\begin{array}{l}\text { Post-Intervention } \\
(\mathrm{n}=20)\end{array}$} & \multirow[t]{2}{*}{$t$} & \multirow[t]{2}{*}{$p$-value } \\
\hline & $\overline{\bar{x}}$ & S.D. & $\overline{\bar{x}}$ & S.D. & & \\
\hline TB knowledge & 16.55 & 1.93 & 18.35 & 1.27 & 3.6 & $.002 *$ \\
\hline Attitudes toward TB care & 3.85 & 0.23 & 4.77 & 0.20 & 13.10 & $.000 *$ \\
\hline TB care skills & 3.51 & 0.34 & 4.73 & 0.21 & 14.54 & $.000 *$ \\
\hline
\end{tabular}

$* p<.05$

Table 3. Comparisons of TB Knowledge, Attitudes toward TB Care, and TB Care Skills at the Baseline and Post-Test in the Control Group

\begin{tabular}{lllllll}
\hline \multirow{2}{*}{ Competencies } & \multicolumn{2}{l}{$\begin{array}{l}\text { Baseline } \\
(\mathbf{n = 2 0})\end{array}$} & \multicolumn{5}{l}{$\begin{array}{l}\text { Post-Intervention } \\
(\mathbf{n = 2 0 )}\end{array}$} & \multicolumn{1}{c}{$\boldsymbol{t}$} & $\boldsymbol{p}$-value \\
\cline { 2 - 7 } & $\overline{\boldsymbol{x}}$ & S.D. & $\overline{\boldsymbol{x}}$ & S.D. & & \\
\hline TB knowledge & 15.50 & 2.28 & 15.70 & 1.49 & .32 & .746 \\
Attitude toward TB care & 3.71 & .24 & 4.40 & .24 & 9.52 & $.000^{*}$ \\
TB care skills & 3.43 & .27 & 4.19 & .20 & 12.14 & $.000^{*}$ \\
\hline
\end{tabular}

${ }^{*} p<.05$.

The mean scores of TB knowledge, attitude towards TB care, and TB care skills in the experimental and control groups at the baseline were not different; whereas the scores of these three competencies at the post-intervention were significantly higher in the experimental group, compared to the control group $(p<.05)$ (see Table 4$)$.

Table 4. Comparison of Mean Scores of TB Knowledge, Attitudes toward TB care, and TB Care Skills before and after applying intervention between experimental and control group

\begin{tabular}{|c|c|c|c|c|c|c|}
\hline \multirow[t]{2}{*}{ Competencies } & \multicolumn{2}{|c|}{$\begin{array}{l}\text { Experimental group } \\
(\mathbf{n}=\mathbf{2 0})\end{array}$} & \multicolumn{2}{|c|}{$\begin{array}{l}\text { Control group } \\
(\mathrm{n}=20)\end{array}$} & \multirow[t]{2}{*}{$t$} & \multirow[t]{2}{*}{$p$-value } \\
\hline & $\overline{\bar{x}}$ & S.D. & $\overline{\bar{x}}$ & S.D. & & \\
\hline \multicolumn{7}{|l|}{ TB knowledge } \\
\hline Pre-intervention & 16.55 & 1.93 & 15.50 & 2.28 & 1.57 & .125 \\
\hline Post-intervention & 18.35 & 1.27 & 15.70 & 1.49 & 6.05 & $.000^{*}$ \\
\hline \multicolumn{7}{|c|}{ Attitudes toward TB care } \\
\hline Pre-intervention & 3.84 & 0.23 & 3.71 & .24 & 1.71 & .095 \\
\hline Post-intervention & 4.77 & 0.20 & 4.40 & .24 & 5.24 & $.000^{*}$ \\
\hline \multicolumn{7}{|l|}{ TB care skills } \\
\hline Pre-intervention & 3.51 & 0.34 & 3.43 & .27 & .766 & .449 \\
\hline Post-intervention & 4.73 & 0.21 & 4.19 & .20 & 8.12 & $.000^{*}$ \\
\hline
\end{tabular}




\section{Discussion}

According to the results of this study, the mean scores of TB knowledge, attitude towards TB care, and TB care skills in the experimental groups at the post-intervention were higher than those of mean scores in the control group. In the experimental group, the mean scores of these three competencies at the baseline and postintervention were significantly different. This indicated that the CDP effectively enhanced TB care competencies of VHVs in the experimental group. This finding was consistent with previous studies indicating the positive effects of training programs integrating the principles of empowerment with community-based TB care on VHVs' competencies (Chuaihom, 2018; Lukman, Ibrahim, Yani, Sari, \& Juniarti, 2019; Poonsawas, 2014; Rohana, Jauhar, Rachmawati, \& Kusumawardani, 2019; Rueankham, 2019; Waraeitipa, Chitreechur, \& Kasatpibal, 2012).

Poonsawas (2014) indicated that VHVs who received the empowerment program gained higher levels of knowledge about home medicine administration for the elderly with chronic illness. Waraeitipa et al. (2012) claimed that health volunteers who participated in the AIC program enhanced their knowledge and skill on TB screening, compared to those who only received routine training. Similarly, Rueankham (2019) represented that health volunteers who were trained through the participatory action research process had higher knowledge scores about TB care and screening, as well as scores on TB screening skills at the end of the program, compared to the beginning of the program. Chuaihom (2018) also showed that VHVs who were trained for TB care were more likely to exhibit TB care skills at higher levels. To promote community-based TB care, healthcare professionals, must therefore, train VHVs on how to provide effective TB care for TB patients and people in the communities.

Using community health volunteers for TB control was an effective strategy for lower-income countries; therefore, empowered community health volunteers could help healthcare professionals to screen new TB cases, provide DOT to registered TB cases, provide health education to people in the community, enhance public awareness of TB transmission, and decrease stigma within the communities (Rohana et al., 2019). Furthermore, Lukman et al. (2019) proved that the effective TB care training program for community health volunteers was the community-based TB care that allowed community health volunteers to share their voices to healthcare professionals, which then resulted in motivating and empowering healthcare professionals to work on their assigned activities. Therefore, to maximize VHVs' TB care competencies, healthcare professionals need to integrate the principles of empowerment and community-based TB care in training programs.

\subsection{Study Limitations}

A short-term design, generalizability, and gender bias were the main limitations of the study. Although the intervention of this study was conducted in a short period, the desired outcomes occurred after the intervention. Due to this, futuristic studies may design a longer follow-up period in order to evaluate the effectiveness of the intervention on long-term TB care competencies. Since this study was a quasi-experimental design in only one small village, the findings may not be generalizable to other settings. In addition, there was limited to mitigate gender bias because the majority of VHVs in the research setting were female. Despite efforts to recruit more male participants, only female participants provided consented to participate in the study.

\section{Conclusions}

Per the findings of the study, the CDP intervention that integrated the principles of empowerment and communitybased TB care was an effective strategy to enhance VHVs' TB care competencies. Since the challenges exist for healthcare professionals to select the most appropriate and effective TB training strategies, findings of this study can be used to guide healthcare professionals for incorporating these two principles in TB training programs which enhance TB care competencies of community health volunteers.

\section{Contributions}

Study Design: JC, DS, PM

Data Collection: JC, PM

Data Analysis: JC, PM, DS

Manuscript Writing: JC, DS, PM, PT

\section{Ethical Approval}

Research approval for the study was given by the Ethics Review Committee, Boromarajajonani Collage of Nursing, Trang (ERC approval No: 30/2018).

\section{Funding}

This study was funded by the Praboromarajchanok Institute for Health Workforce Development (PIHWD), 
Ministry of Public Health, Thailand.

\section{Competing Interests Statement}

The authors declare that they have no conflict interests.

\section{References}

Balogun, M., Sekoni, A., Meloni, S. T., Odukoya, O., Onajole, A., Longe-Peters, O., ... \& Kanki, P. J. (2015). Trained community volunteers improve tuberculosis knowledge and attitudes among adults in a periurban community in southwest Nigeria. The American journal of tropical medicine and hygiene, 92(3), 625-632. https://doi.org/10.4269/ajtmh.14-0527

Bureau of Tuberculosis, Department of Disease Control. (2017). Systematic screening for active TB and drugresistant TB. Bangkok, Thailand: Aksorn graphic and design publishing house. (in Thai).

Bureau of Tuberculosis, Department of Disease Control. (2018). National tuberculosis control program guideline. Bangkok, Thailand: Aksorn graphic and design publishing house. (in Thai).

Choowong, J., Tillgren, P., \& Söderbäck, M. (2016). Thai district Leaders' perceptions of managing the direct observation treatment program in Trang Province, Thailand. BMC public health, 16(1), 653. https://doi.org/10.1186/s12889-016-3341-1

Choowong, J. Tillgren, P., \& Söderbäck, M. (2017). Thai people living with tuberculosis and how they adhere to treatment: A grounded theory study. Nursing \& Health Sciences, 19(4), 436-443. https://doi.org/10.1111/nhs. 12362

Choowong, J., Tillgren, P., \& Söderbäck, M. (2018). Directly Observed Therapy Providers' Practices When Promoting Tuberculosis Treatment in a Local Thai Community. Journal of Public Health in Developing Countries, 4(1), 458-466.

Choowong, J., Suphasri, J., \& Sawatdee, D. (2019). The challenges in the practice of directly observed therapy in a local community. The Southern College Network Journal of Nursing and Public Health, 6(3), 165-174. (in Thai).

Chuaihom, N. (2018). Factors related to the prevention and control of tuberculosis among village health volunteers in Thathongmai, Kanchanadit, Suratthani. Region 11 Medical Journal- วารสาร วิชาการ แพทย์ เขต 11, 32(1), 899-906.

Escott, S., \& Walley, J. (2005). Listening to those on the frontline: lessons for community-based tuberculosis programmes from a qualitative study in Swaziland. Social science \& medicine, 61(8), 1701-1710. https://doi.org/10.1016/j.socscimed.2005.03.040

Department of Disease Control. (2017). National Strategic Plan on Tuberculosis B.E.2560-2564 (2017-2021). Retrieved from https://www.tbthailand.org/documents.html (in Thai).

Gibson, C. H. (1991). A Concept analysis of empowerment. Journal of Advance Nursing, 16, 354-361. https://doi.org/10.1111/j.1365-2648.1991.tb01660.x

Kaji, A., Thi, S. S., Smith, T., Charunwatthana, P., \& Nosten, F. H. (2015). Challenges in tackling tuberculosis on the Thai-Myanmar border: findings from a qualitative study with health professionals. BMC health services research, 15(1), 464. https://doi.org/10.1186/s12913-015-1129-0

Koyanagi, A., Vancampfort, D., Carvalho, A. F., DeVylder, J. E., Haro, J. M., Pizzol, D., ... \& Stubbs, B. (2017). Depression comorbid with tuberculosis and its impact on health status: cross-sectional analysis of community-based data from 48 low-and middle-income countries. BMC medicine, 15(1), 209. https://doi.org/10.1186/s12916-017-0975-5

Lewis, C. P., \& Newel, J. N. (2009). Improving tuberculosis care in low income countries-a qualitative study of patients' understanding of "patient support" in Nepal. Biomed Central Public Health, 9(190), 1-8. https://doi.org/10.1186/1471-2458-9-190

Lukman, M., Ibrahim, K., Yani, D. I., Sari, S. P., \& Juniarti, N. (2019). Exploring strategies to improve the performance of community health volunteers for tuberculosis care and prevention: A qualitative study. International Journal of Community Based Nursing and Midwifery, 7(4), 270-278. https://doi.org/10.30476/IJCBNM.2019.81353.0.

Muksa-As, S., \& Sumpowthong, K. (2017). Effects of a health promotion program by applying the theory of empowerment in new smear positive pulmonary tuberculosis patients. Journal on Science and Technology for 
Development, 24(1), 13-27. (in Thai).

Namwat, C. et al. (2018). Return on investment of ending TB strategies in Thailand: A cost-benefit analysis. Retrieved from http://www.hitap.net/wp-content/uploads/2018/08/ Full-report_TB.pdf. (in Thai).

Ngamvithayapong-Yanai, J., Luangjina, S., Nedsuwan, S., Kantipong, P., Wongyai, J., \& Ishikawa, N. (2013). Engaging women volunteers of high socioeconomic status in supporting socioeconomically disadvantaged tuberculosis patients in Chiang Rai, Thailand. Western Pacific Surveillance and Response Journal, 4(1), 34-38. (in Thai). https://doi.org/10.5365/wpsar.2012.3.4.013

Poonsawas, Y. (2014). The outcomes of empowerment program of village health volunteers in home medication usage amongst the elderly with chronic illnesses in Ratchaburi province (Master's thesis). Retrieved from http://library.christian.ac.th/thesis/ document/T036438.pdf (in Thai)

Rakwong, N., Sillabutra, J., \& Keiwharnka, B. (2010). Performance of village health volunteers on tuberculosis prevention in Mahachanachai district, Yasothon province, Thailand. Journal of Public Health and Development, 8(3), 252-264.

Rohana, I. G. A. P. D. Jauhar, M. Rachmawati, R., \& Kusumawardani, L. H. (2019). Empowering community health volunteer on community-based tuberculosis case management programs in lower income countries: A systematic review. Journal of Community Empowerment for Health, 2(2), 172-180. https://doi.org/10.22146/jcoemph.47148

Rueankham, C. (2019). The development of health volunteers' competency for tuberculosis screening in community in Nam Pat District, Uttaradit province. Journal of Disease Prevention and Control: DPC. 2, Phitsanulok, 6(1), 48-61. (in Thai).

Somrit, N. (2015). Performance and readiness of village health volunteers on supervision of tuberculosis patients by directly observed treatment short-course, Kokha distruct, Lampang province (Master's thesis). Retrieved from http://ethesisarchive.library. tu.ac.th/thesis/. (in Thai).

Tanimura, T., Jaramillo, E., Weil, D., Raviglione, M., \& Lönnroth, K. (2014). Financial burden for tuberculosis patients in low- and middle-income countries: A systematic review. The European Respiratory Journal, 43(6), 1763-1775. https://doi.org/10.1183/09031936.00193413

Tengland, P. A. (2008). Empowerment: A conceptual discussion. Health Care Analysis, 16, 77-96. https://doi.org/10.1007/s10728-007-0067-3

Trang Provincial Public Health Office. (2019). Annual report 2018. Trang, Thailand: Trang Provincial Public Health Office. (in Thai)

Vachirabunchong, C. (2015). Village health volunteer's readiness in controlling and taking care of tuberculosis patients by directly observed therapy short course in Sai Ngam district, Kamphaeng Phet province (Master's thesis). Retrieved from http://cmuir. cmu.ac.th /bitstream/6653943832/27607/2/ mph0942cv_abs.pdf. (in Thai)

Waraeitipa, T., Chitreechur, J., \& Kasatpibal, N. (2012). Effects of implementing an action Plan based on AIC technique on knowledge and efficiency of pulmonary tuberculosis screening among prison health volunteers. Nursing Journal, 39(3), 66-76. (in Thai).

World Health organization. (2015). ENGAGE-TB: integrating community-based tuberculosis activities into the work of nongovernmental and other civil society organizations: training of community health workers and community volunteers: Facilitators' guide. Retrieved from https://apps.who.int/iris/bitstream /handle/10665/178160/978924 1509176_eng.pdf

World Health Organization. (2018). Global tuberculosis report 2018. Retrieved from https://Global tuberculosis report2018apps.who.int/medicinedocs/documents /s23553en/s23553 en.pdf

\section{Copyrights}

Copyright for this article is retained by the author(s), with first publication rights granted to the journal.

This is an open-access article distributed under the terms and conditions of the Creative Commons Attribution license (http://creativecommons.org/licenses/by/4.0/). 